\title{
Stability-Indicating Validated HPLC Method for Analysis of Berberine Hydrochloride and Trimethoprim in Pharmaceutical Dosage Form
}

\author{
Jing-Chun Wang, ${ }^{1}$ Qi Zhang, ${ }^{1,2}$ and De-Fu Cai ${ }^{1}$ \\ ${ }^{1}$ Institute of Medicine and Drug Research, Qiqihar Medical University, 333 Bukui Street, Jianhua District, \\ Heilongjiang Province, Qiqihar 161006, China \\ ${ }^{2}$ Basic Medical Science College, Qiqihar Medical University, Qiqihar 161006, China \\ Correspondence should be addressed to De-Fu Cai; caidefu1981@gmail.com
}

Received 8 August 2012; Revised 13 October 2012; Accepted 29 October 2012

Academic Editor: Jose Alberto Pereira

Copyright (C) 2013 Jing-Chun Wang et al. This is an open access article distributed under the Creative Commons Attribution License, which permits unrestricted use, distribution, and reproduction in any medium, provided the original work is properly cited.

\begin{abstract}
A stability-indicating HPLC method was developed and validated for the determination of berberine hydrochloride and trimethoprim in pharmaceutical dosage form in the presence of degradation products. The proposed RP-HPLC method utilizes an Agilent TC-C18, $4.6 \mathrm{~mm} \times 250 \mathrm{~mm}, 5 \mu \mathrm{m}$, column using a mobile phase consisting of acetonitrile-50 mM potassium dihydrogen phosphate $(30: 70, \mathrm{v} / \mathrm{v}, \mathrm{pH}$ adjusted to 3 with orthophosphoric acid) at a flow rate of $1.0 \mathrm{~mL} / \mathrm{min}$ and UV detection at $271 \mathrm{~nm}$. The linearity of berberine hydrochloride and trimethoprim was in the range of 2 to $60 \mu \mathrm{g} / \mathrm{mL}(r=0.9996)$ and 1 to $30 \mu \mathrm{g} / \mathrm{mL}$ $(r=0.9995)$, respectively. Repeatability and intermediate precisions were also determined with percentage relative standard deviation (\% RSD) less than $2.0 \%$. The limits of detection were found to be $9.8 \mathrm{ng} / \mathrm{mL}$ for berberine hydrochloride and $2.5 \mathrm{ng} / \mathrm{mL}$ for trimethoprim. The mean recoveries for berberine hydrochloride and trimethoprim were 99.8 and $98.8 \%$, respectively. The stability of the two drugs was determined under different conditions and the proposed method has shown effective separation for their degradation products. And the proposed assays method can thus be considered stability-indicating.
\end{abstract}

\section{Introduction}

Berberine hydrochloride (BBR) (see Figure 1(a)), a kind of isoquinoline alkaloid, is a commonly used drug extracted from a variety of Chinese herbs, including Coptidis rhizoma, Phellodendron chinense schneid, and Phellodendron amurense [1]. It exhibited a variety of biological and pharmacological actions, such as antidiabetic activity [2, 3], antitumor properties [4-7], bacteriocidal property $[8,9]$, as well as antiatherosclerotic activity [10] and anti-inflammatory effects $[11,12]$. Trimethoprime (TMP) (see Figure 1(b)), a dihydrofolate-reductase inhibitor, is well known as antibacterial drug inhibiting the biosynthesis of nucleic acids and proteins essential to many bacteria [13]. It is commonly used for the prevention and treatment of a variety of infections, such as urinary, respiratory, and gastrointestinal infections $[14,15]$. BBR and TMP have been used in combined capsule preparation as a gastrointestinal remedy for many years in China. It is commonly used for the treatment of diseases such as gastroenteritis and bacillary dysentery on the base of several potential advantages of the combination of the two drugs over each one individually [16]. With the increasing clinical coadministration of BBR and TMP as therapy for many diseases, the simultaneous analysis of both drugs in one dosage form would facilitate their applications. Up to now, considerable methods have been described on the analysis of BBR and TMP. Concerning BBR the following techniques were applied, such as HPLC [17-19], capillary electrophoresis [20], resonance Rayleigh scattering [21], spectrofluorimetry [22], electrochemical analysis [23], and chemiluminescence [24], whereas the analytical methods for TMP have been based mainly on HPLC [25-27], UV-visible spectroscopy $[28,29]$ including derivative procedures $[13]$ and infrared spectroscopy [30]. However, only few HPLC methods were 
<smiles>COc1ccc2cc3[n+](cc2c1OC)-c1cc2c(cc1CC3)OCO2</smiles>

(a)<smiles>COc1cc(Cc2cnc(N)nc2N)cc(OC)c1OC</smiles>

(b)

FIgURE 1: The chemical structures of (a) berberine hydrochloride and (b) trimethoprim.

documented for the simultaneous determination of BBR and TMP, and also these methods utilize complex internal standard quantification and lack of proper validation of the method. Hence these methods are not feasible and economical for pharmaceutical industry and routine analysis. Stability testing forms are an important part of the process of drug development, since it provides evidence on how the quality of drug substance or drug product varies with time under the influence of a variety of environmental factors, such as humidity, temperature, and light [31]. Although many stability-indicating methods have been reported for assays of various drugs in drug products containing one active drug substance, but only few stability-indicating methods are reported for the assay of combination drug products [32]. As far as we are aware, no stability-indicating method was reported for the simultaneous determination of BBR and TMP to date. Since BBR and TMP have been used to prevent and treat a variety of diseases, it is necessary to develop a new stability-indicating method for the accurate and quantifiable estimation of BBR and TMP in the presence of their related impurities. Therefore, at present, it is the first time for us to develop and validate a simple, accurate, and reproducible stability-indicating LC method for the simultaneous determination of BBR and TMP in pharmaceutical preparation.

\section{Experimental}

2.1. Chemicals and Reagents. Combined capsules (containing $100 \mathrm{mg}$ of BBR and $50 \mathrm{mg}$ of TMP) and standard samples of $\mathrm{BBR}$ and TMP (purity $\geq 98 \%$ ) were obtained from Longhui Pharmaceutical Ltd. (Qiqihar, China). HPLC-grade acetonitrile was purchased from Dikma Technology Inc. (Richmond, USA). Analytical-grade potassium dihydrogen phosphate and orthophosphoric acid were purchased from
Concord Technology Co. Inc. (Tianjin, China). Analyticalgrade sodium hydroxide, hydrochloric acid, and hydrogen peroxide were purchased from Kermel Chemical Reagent Co., Ltd. (Tianjin, China).

2.2. Chromatographic Apparatus and Conditions. Chromatographic separations were performed using the Waters HPLC system (Massachusetts, USA) consisted of a 600 liquid pump, a 2487 dual $\lambda$ absorbance detector, a 717 autosampler, an autoelectronic degasser and a computer with an Empower software for analysis of the HPLC data.

The analytes were separated on a $4.6 \mathrm{~mm} \times 250 \mathrm{~mm}, 5 \mu \mathrm{m}$ particle, Agilent TC-C18 analytical column with acetonitrile: $50 \mathrm{mM}$ potassium dihydrogen phosphate $30: 70(\mathrm{v} / \mathrm{v}, \mathrm{pH}$ adjusted to 3 with orthophosphoric acid) as isocratic mobile phase at a flow rate of $1.0 \mathrm{~mL} / \mathrm{min}$. The injection volume was $20 \mu \mathrm{L}$ and the $271 \mathrm{~nm}$ was selected as the detection wavelength. The chromatographic signals were monitored and integrated by use of Waters Empower Chrom software.

2.3. Preparation of Standard Solution. $40 \mathrm{mg}$ of BBR and $20 \mathrm{mg}$ of TMP were weighed accurately and transferred to independent $100 \mathrm{~mL}$ volumetric flasks. Both drugs were dissolved in $100 \mathrm{~mL} 100: 1(\mathrm{v} / \mathrm{v})$ methanol-hydrochloric acid to yield $400 \mu \mathrm{g} / \mathrm{mL}$ and $200 \mu \mathrm{g} / \mathrm{mL}$ standard stock solutions for each. The standard working solutions of BBR in the concentration range $2-60 \mu \mathrm{g} / \mathrm{mL}$ and TMP in the concentration range $1-30 \mu \mathrm{g} / \mathrm{mL}$ were prepared by dilution of the standard stock solutions in the same solvent. All the stock and working solutions were stored at $4^{\circ} \mathrm{C}$ and brought to room temperature before use.

2.4. Preparation of Sample Solution. Twenty capsules (labeled to contain $100 \mathrm{mg}$ of BBR and $50 \mathrm{mg}$ of TMP per capsule), were accurately weighed, crushed to a fine powder, and then mixed thoroughly. An accurately weighed portion of the powder equivalent to $40 \mathrm{mg}$ of BBR and $20 \mathrm{mg}$ of TMP were transferred to a $100 \mathrm{~mL}$ volumetric flask containing $70 \mathrm{~mL}$ $100: 1(\mathrm{v} / \mathrm{v})$ methanol-hydrochloric acid and sonicated for $30 \mathrm{~min}$. Then the samples were made up to volume with the same solvent and filtered through $0.22 \mu \mathrm{m}$ filter. This solution was further diluted by the same solvent to achieve $40 \mu \mathrm{g} / \mathrm{mL}$ of BBR and $20 \mu \mathrm{g} / \mathrm{mL}$ of TMP.

2.5. Validation of the Method. The method was validated for calibration linearity, precision, accuracy, solution stability, limit of detection (LOD), limit of quantification (LOQ), specificity-forced degradation studies and, robustness.

2.5.1. System Suitability. To ensure that the HPLC testing system was suitable for the intended application, the system suitability was assessed by six replicate analyses of system suitability test solution and the chromatographic parameters were evaluated. The acceptance criteria were not more than $2.0 \%$ for the \% RSD of the peak areas and retention times, not more than 1.2 for the tailing factor of the analyte peaks. 
2.5.2. Calibration and Linearity. Six levels of calibration standard solutions were prepared from the stock solutions at concentrations from 2 to $60 \mu \mathrm{g} / \mathrm{mL}$ for BBR and from 1 to $30 \mu \mathrm{g} / \mathrm{mL}$ for TMP to encompass the expected concentration in measured samples. Calibration curves were constructed by plotting peak areas versus concentrations of BBR and TMP and then subjected to treat by least-squares linear regression analysis.

2.5.3. Limits of Detection and Quantification. The limit of detection (LOD) and limit of quantitation (LOQ) were defined as the lowest concentration of analyte in a sample that can be detected and quantified. The standard solutions of BBR and TMP for LOD and LOQ were prepared by diluting them with $100: 1(\mathrm{v} / \mathrm{v})$ methanol-hydrochloric acid sequentially. The LOD and LOQ were determined by the signal-to-noise $(\mathrm{S} / \mathrm{N})$ ratio for each compound through analyzing a series of diluted solutions until the $\mathrm{S} / \mathrm{N}$ ratio yield 3 for LOD and 10 for LOQ, respectively.

2.5.4. Precision. The precision of the developed method was assessed by performing repeatability (intraday) and intermediate (interday) precision. Repeatability of the assay method was investigated by using three replicate sample solutions at three concentration levels $(35,40$ and $45 \mu \mathrm{g} / \mathrm{mL}$ for BBR and 15,20 , and $25 \mu \mathrm{g} / \mathrm{mL}$ for TMP) in one day and the $\%$ RSD was calculated to determine repeatability precision. These studies were also performed on three consecutive days to determine intermediate precision.

2.5.5. Accuracy. To confirm the method's accuracy, recovery experiments were checked by standard addition method. The recovery experiments were performed in triplicate at 80 , 100 , and $120 \%$ concentration levels of the amount of the analytes in the pre-analyzed sample solutions. The percentage recovery in each level $(n=3)$ and mean percentage recovery $(n=9)$ were calculated.

2.5.6. Robustness. The robustness of the method was investigated by testing the susceptibility of measurements under deliberate change conditions including change of flow rate $(1 \pm 0.1 \mathrm{~mL} / \mathrm{min})$, the percentage of acetonitrile concentration $(30 \pm 1 \%)$, and the $\mathrm{pH}$ value $(3.0 \pm 0.1)$. The degrees of reproducibility for sample solution were evaluated under these original and robustness conditions.

2.5.7. Specificity-Forced Degradation Studies. The forced degradation studies were executed to demonstrate whether the analytical method were stability-indicating and could unequivocally assess the analyte in the presence of impurities and degradation products. Combined capsule and pure drug ingredients of BBR and TMP were stressed under thermolytic, photolytic, acid/alkali hydrolytic, and oxidative stress conditions to result in expect $20-80 \%$ partial degradation of the drugs. All solutions used in forced degradation studies were prepared by dissolving pure drug ingredients and drug product in small amount of $100: 1(\mathrm{v} / \mathrm{v})$ methanolhydrochloric acid and then diluted with either $3 \%$ hydrogen peroxide, $1 \mathrm{~N}$ hydrochloric acid, or $1 \mathrm{~N}$ sodium hydroxide to achieve concentration of $200 \mu \mathrm{g} / \mathrm{mL}$ and $100 \mu \mathrm{g} / \mathrm{mL}$ for BBR and TMP, respectively. However, the thermolytic and photolytic degradation samples were carried out in solid state. After expose to the thermolytic and photolytic conditions, the samples were diluted in 100:1 (v/v) methanol-hydrochloric acid to yield initial concentrations of $20 \mu \mathrm{g} / \mathrm{mL}$ and $10 \mu \mathrm{g} / \mathrm{mL}$ for BBR and TMP.

2.5.8. Oxidation Studies. Solutions for use in oxidation studies were prepared by dissolving pure drug ingredients and drug product in small amount of $100: 1(\mathrm{v} / \mathrm{v})$ methanolhydrochloric acid and then diluted with $3 \%$ hydrogen peroxide, later the mixtures were kept at $80^{\circ} \mathrm{C}$ for $2 \mathrm{~h}$ in a water bath.

2.5.9. Acid and Alkali Hydrolysis Studies. For acid and alkali hydrolysis, solutions were prepared by dissolving pure drug ingredients and drug product in small amount of 100:1 $(\mathrm{v} / \mathrm{v})$ methanol-hydrochloric acid and then diluted with $1 \mathrm{~N}$ hydrochloric acid or $1 \mathrm{~N}$ sodium hydroxide, later the mixtures were kept at $80^{\circ} \mathrm{C}$ for $5 \mathrm{~h}$ in a water bath.

2.5.10. Thermolytic Degradation Studies. For thermal stress testing, the powders of pure drug ingredients and drug product were placed in a convection oven and exposed to heat at $100^{\circ} \mathrm{C}$ for $36 \mathrm{~h}$.

2.5.11. Photolytic Degradation Studies. For photo stress testing, the powders of pure drug ingredients and drug product were placed in a light cabinet and exposed to sunlight lamp $(5000 \pm 500 \mathrm{l} x)$ for $100 \mathrm{~h}$.

2.5.12. Solution Stability. In order to demonstrate the stability of both standard and sample solutions, the solutions were tested at intervals of $6 \mathrm{hr}$ over a period of $48 \mathrm{hr}$ at room temperature. The stability of solutions was appreciated by comparing results of peak area and retention time.

\section{Results and Discussion}

3.1. HPLC Method Development and Optimization. Optimization of the HPLC conditions was guided by the key aim to achieve good resolution of both drugs in presence of degradation products and impurities within as short time as possible, especially when many samples need to be analyzed. To achieve above aim different chromatographic columns like Agilent TC-C18, Inertsil ODS-3 C18, and Dikma DiamonsiC18, different mobile phases containing buffers like phosphate and ammonium acetate and with different volumes of methanol or acetonitrile as organic modifier in different $\mathrm{pH}$ (3-5) were considered. While satisfactory resolution between BBR and TMP was achieved on three C18 columns, yet only Agilent TC-C18 was able to separate both drugs in presence of degradation products and impurities. We also investigated the composition, $\mathrm{pH}$, and the flow rate of the 
TABLE 1: Repeatability and intermediate precision data of proposed method.

\begin{tabular}{|c|c|c|c|c|c|}
\hline \multirow[b]{2}{*}{ Compounds } & \multirow[b]{2}{*}{$\begin{array}{l}\text { Concentration } \\
(\mu \mathrm{g} / \mathrm{mL})\end{array}$} & \multicolumn{2}{|c|}{ Repeatability precision } & \multicolumn{2}{|c|}{ Intermediate precision } \\
\hline & & $\begin{array}{c}\text { Concentration measured } \\
(\mu \mathrm{g} / \mathrm{mL}) \\
\text { mean } \pm \text { S.D. }(n=3)\end{array}$ & RSD (\%) & $\begin{array}{c}\text { Concentration measured } \\
(\mu \mathrm{g} / \mathrm{mL}) \\
\text { mean } \pm \text { S.D. }(n=3)\end{array}$ & RSD (\%) \\
\hline \multirow{3}{*}{ Berberine hydrochloride } & 35 & $35.08 \pm 0.05$ & 0.15 & $34.82 \pm 0.43$ & 1.24 \\
\hline & 40 & $40.02 \pm 0.12$ & 0.31 & $39.19 \pm 0.70$ & 1.80 \\
\hline & 45 & $45.15 \pm 0.58$ & 1.29 & $44.71 \pm 0.78$ & 1.74 \\
\hline \multirow{3}{*}{ Trimethoprim } & 15 & $15.01 \pm 0.12$ & 0.77 & $14.80 \pm 0.11$ & 0.74 \\
\hline & 20 & $19.65 \pm 0.28$ & 1.42 & $19.60 \pm 0.35$ & 1.78 \\
\hline & 25 & $25.16 \pm 0.41$ & 1.65 & $25.05 \pm 0.35$ & 1.38 \\
\hline
\end{tabular}

TABLE 2: Recovery data of berberine hydrochloride and trimethoprim from samples.

\begin{tabular}{|c|c|c|c|c|c|}
\hline Compounds & $\begin{array}{c}\text { Added amount } \\
(\mu \mathrm{g} / \mathrm{mL})\end{array}$ & $\begin{array}{c}\text { Original amount } \\
(\mu \mathrm{g} / \mathrm{mL})\end{array}$ & $\begin{array}{c}\text { Found amount } \\
(\mu \mathrm{g} / \mathrm{mL})\end{array}$ & $\begin{array}{c}\text { Recovery } \\
(\%)\end{array}$ & $\begin{array}{c}\text { Mean recovery } \\
(\%)\end{array}$ \\
\hline \multirow{9}{*}{ Berberine hydrochloride } & 12 & 20 & 11.91 & 99.3 & \multirow{9}{*}{99.8} \\
\hline & 12 & 20 & 11.97 & 99.7 & \\
\hline & 12 & 20 & 11.98 & 99.8 & \\
\hline & 20 & 20 & 19.74 & 98.7 & \\
\hline & 20 & 20 & 19.78 & 98.9 & \\
\hline & 20 & 20 & 19.77 & 98.8 & \\
\hline & 28 & 20 & 28.53 & 101.9 & \\
\hline & 28 & 20 & 27.88 & 99.6 & \\
\hline & 28 & 20 & 28.31 & 101.1 & \\
\hline \multirow{9}{*}{ Trimethoprim } & 6 & 10 & 6.07 & 101.2 & \multirow{9}{*}{98.8} \\
\hline & 6 & 10 & 6.03 & 100.5 & \\
\hline & 6 & 10 & 6.11 & 101.8 & \\
\hline & 10 & 10 & 9.81 & 98.1 & \\
\hline & 10 & 10 & 9.85 & 98.5 & \\
\hline & 10 & 10 & 9.75 & 97.5 & \\
\hline & 14 & 10 & 13.82 & 98.7 & \\
\hline & 14 & 10 & 13.46 & 96.1 & \\
\hline & 14 & 10 & 13.60 & 97.2 & \\
\hline
\end{tabular}

mobile phase. After several preliminary experimental chromatographic runs, a mobile phase consisting of acetonitrile$50 \mathrm{mM}$ potassium dihydrogen phosphate $(30: 70 \mathrm{v} / \mathrm{v}, \mathrm{pH} 3)$ at a flow rate of $1.0 \mathrm{~mL} / \mathrm{min}$ was selected for further studies. Finally, the favorable separation in terms of peak symmetry, resolution, reasonable run time was obtained using these experimental conditions. All experiments were performed at ambient temperature. To determine the appropriate wavelength for simultaneous determination of TMP and BBR, UV spectra of the two drugs in 100:1 (v/v) methanolhydrochloric acid were scanned in the range $200-400 \mathrm{~nm}$ through a Shimadzu 2550 spectrophotometer (Tokyo, Japan). From the UV spectra, the maximum absorption wavelengths for TMP and BBR were 271 and $289 \mathrm{~nm}$, respectively. As in combined capsule preparation the content of BBR is two times higher than the TMP, so the wavelength of $271 \mathrm{~nm}$ was selected to obtain similar absorbance for the two drug peaks.

\subsection{Validation of the Method}

3.2.1. System Suitability. The \% RSD of peak areas for six replicate injections of TMP and BBR was 0.75 and $0.16 \%$, respectively. The mean retention time was 3.98 and 13.95 minute $(\% \mathrm{RSD}=1.2 \%, 1.6 \%)$ for $\mathrm{TMP}$ and $\mathrm{BBR}$. The tailing factor for TMP and BBR peaks was 1.14 and 1.15. The efficiency of the column, expressed as the number of theoretical plates for six replicate injections, was $13844 \pm 2434$ and $11030 \pm 1727$ for TMP and BBR. These pretty parameters indicated the suitability of this system. 


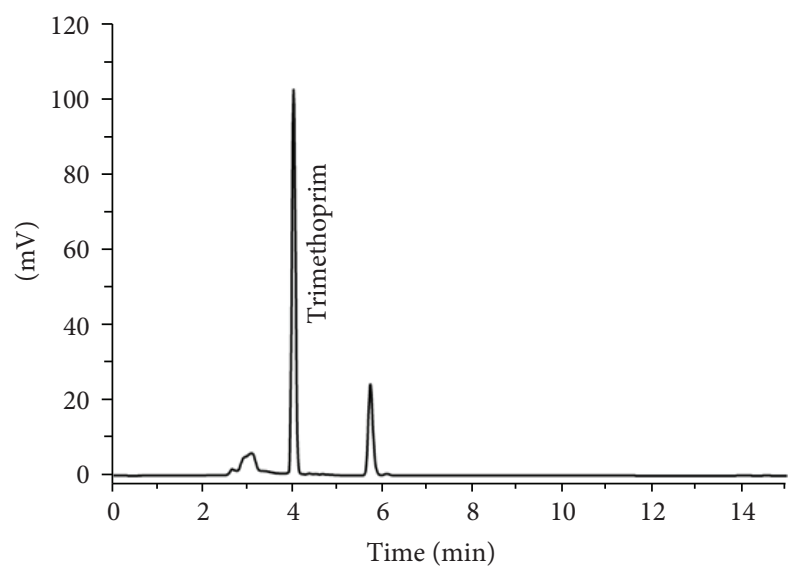

(a)

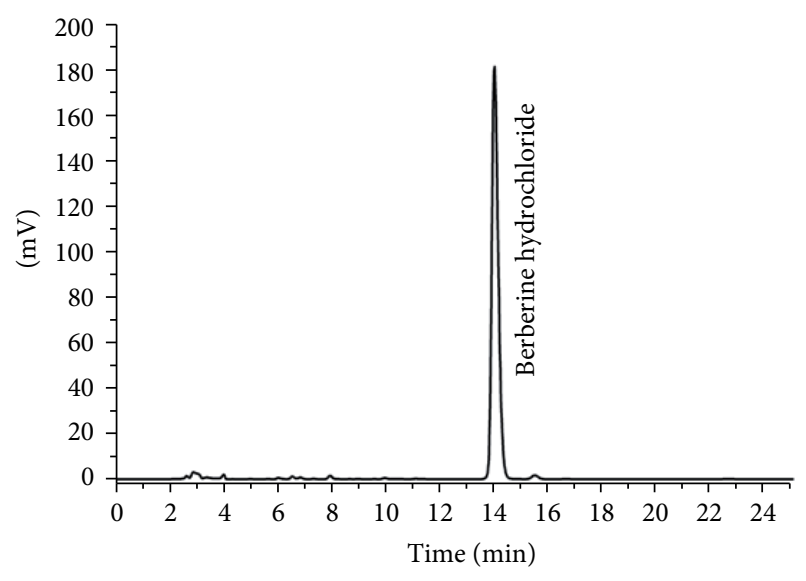

(b)

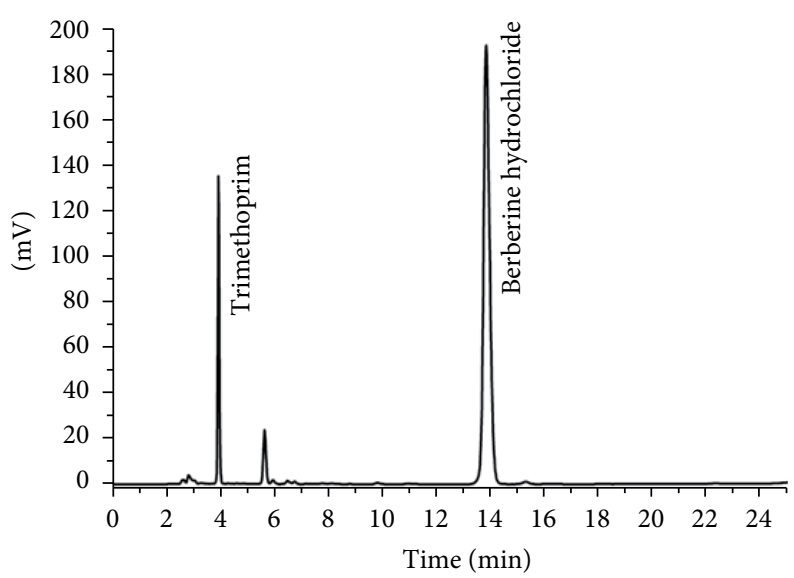

(c)

FIgURE 2: Typical HPLC chromatograms of acid hydrolysis degraded (a) trimethoprim, (b) berberine hydrochloride, and (c) combined capsule solutions.

3.2.2. Calibration and Linearity. Linearity was established by least squares linear regression analysis of the calibration curve. Good linearity between the peak area and concentration of the analyte was obtained throughout the concentration range, and the regression equations were $y=$ $81364 x-25652$ for BBR and $y=35003 x+11462$ for TMP with the correlation coefficients of 0.9996 and 0.9995 , respectively, where $y$ is the response (peak area) and $x$ is the concentration in $\mu \mathrm{g} / \mathrm{mL}$. The results demonstrated that an excellent correlation between the peak area and analyte concentration in the range studied.

3.2.3. Limits of Detection and Quantification. The limits of detection and quantitation were found to be 9.8 and $32.6 \mathrm{ng} / \mathrm{mL}$ for BBR and 2.5 and $8.3 \mathrm{ng} / \mathrm{mL}$ for TMP, respectively. These indicated the sensitivity of the developed method.

3.2.4. Precision. The repeatability and intermediate precisions data are summarized in Table 1 . The results showed that the $\%$ RSDs for repeatability precisions ranged from $0.15-1.29 \%$ and $0.77-1.65 \%$ whereas for intermediate precision they were $1.24-1.80 \%$ and $0.74-1.38 \%$ for BBR and TMP, respectively. These were all within the acceptable range of $2.0 \%$, confirming that the method was sufficiently precise.

3.2.5. Accuracy. As shown in Table 2, recoveries of standard addition method were found to be $98.7-101.9 \%$ for BBR and 96.1-101.8\% for TMP in all three levels. The mean recoveries for both drugs were 99.8 and $98.8 \%$, respectively. Excellent recoveries were made at each added level.

3.2.6. Robustness. The results obtained from assay of the sample solutions were not affected by varying the acetonitrile concentration $(30 \pm 1 \%)$ and the $\mathrm{pH}$ value $(3.0 \pm 0.1)$ conditions and in accordance with the results for original conditions. \% RSD values for three replicate assays of sample solution under deliberate change acetonitrile concentration and the $\mathrm{pH}$ value were less than $2.0 \%$. While the small 


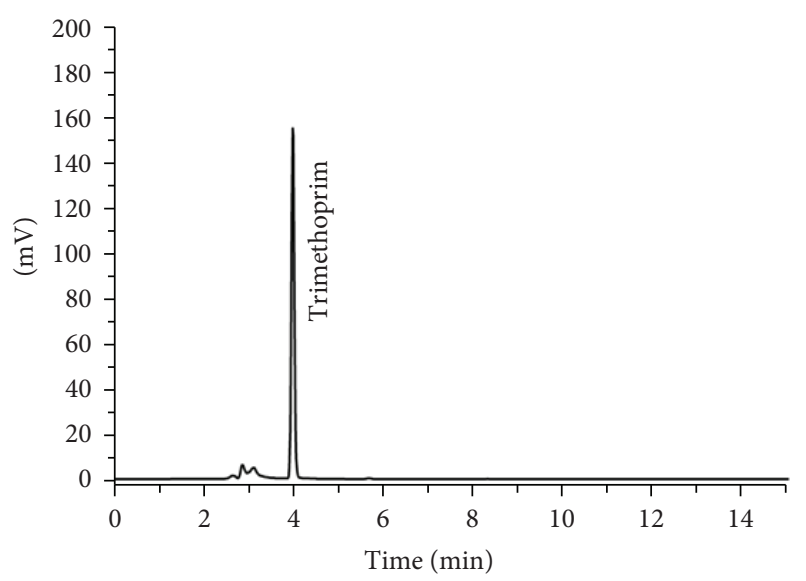

(a)

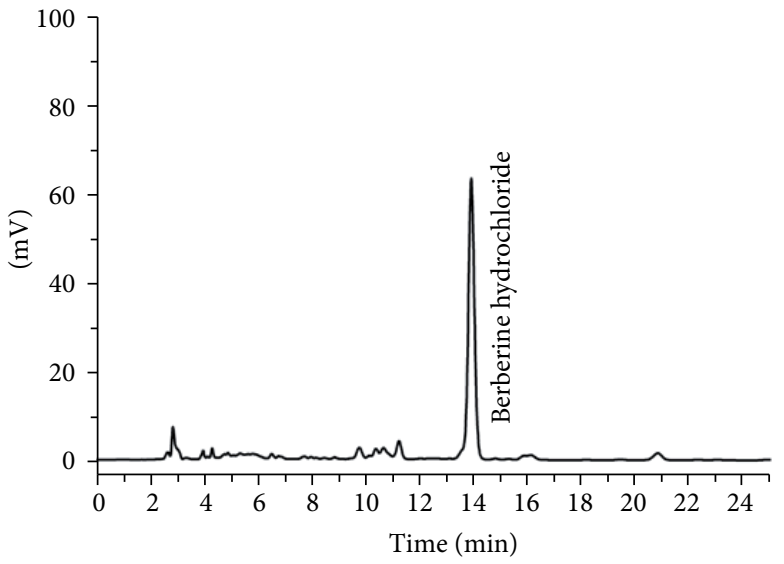

(b)

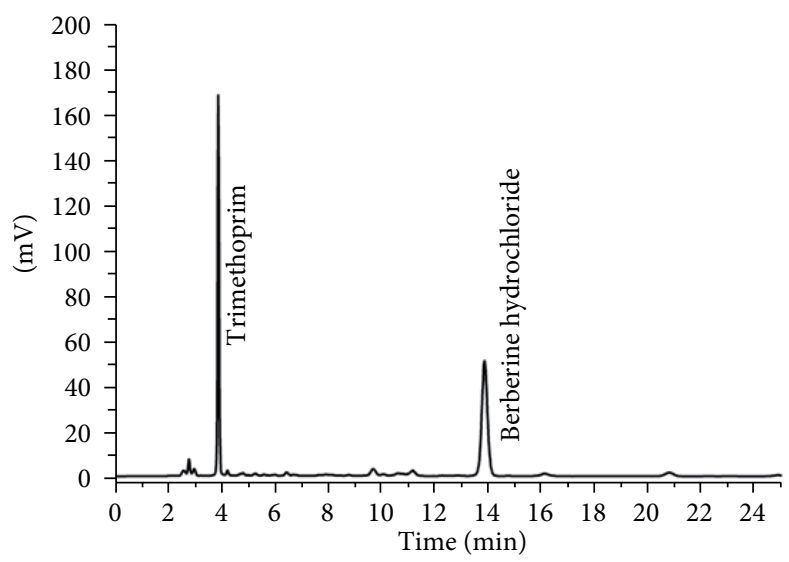

(c)

FIGURE 3: Typical HPLC chromatograms of alkali hydrolysis degraded (a) trimethoprim, (b) berberine hydrochloride, and (c) combined capsule solutions.

change in flow rate condition $(1 \pm 0.1 \mathrm{~mL} / \mathrm{min})$ resulted in the dramatic change in peak size.

3.2.7. Specificity-Forced Degradation Studies. Typical chromatograms obtained from assay of stressed the combined capsule and two pure drugs are shown in Figures 2, 3, and 4. The degradation products of the BBR and TMP were indicated to be similar for the two pure drug ingredients and their combined capsule. The TMP was found to be more sensitive to acid hydrolysis than BBR. During the acid hydrolysis process, about $21 \%$ of TMP was degraded and one main degradation peak was observed at $5.73 \mathrm{~min}$, while only about $4 \%$ of BBR was degraded and no obvious degradation peak was observed. However, on the opposite, BBR was found to be more sensitive to alkali hydrolysis than TMP. During the alkali hydrolysis process, about $69 \%$ of BBR was decomposed and many small degradation peaks were observed, while no degradation happened to TMP. However, both the BBR and TMP were sensitive to oxidative stress condition. About $79 \%$ of TMP and $57.5 \%$ of BBR were degraded and many degradation products were observed. No decomposition was seen on exposure to light and heat in solid state for both the BBR and TMP during the thermolytic and photolytic degradation process. These results proven capable of separating BBR and TMP from the main impurities and degradation products and indicated a high degree of specificity of this method.

3.2.8. Solution Stability. The results indicate that for both solutions, the retention times and peak areas of BBR and TMP remained almost unchanged (\% RSD less than 2.0) and no unknown peak was formed during the indicated period. This indicated that all solutions remained stable for at least $48 \mathrm{hr}$, which was sufficient to complete the entire analytical process.

3.3. Assay. This proposed method was applied to the determination of BBR and TMP in commercially combined capsule. A typical HPLC chromatogram is shown in Figure 5 for such determination. Satisfactory results were obtained as the mean percentages found for BBR and TMP were $97.96 \%$ $(\% \mathrm{RSD}=1.35 \%)$ and $98.3 \%(\% \mathrm{RSD}=1.36 \%)$ of label claim, respectively. The result of the assay indicated that the method could be adopted for the assay of BBR and TMP 


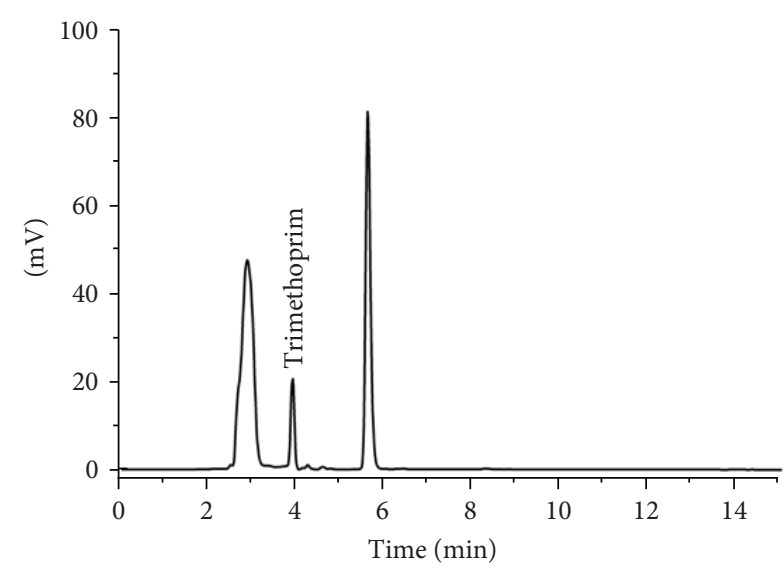

(a)

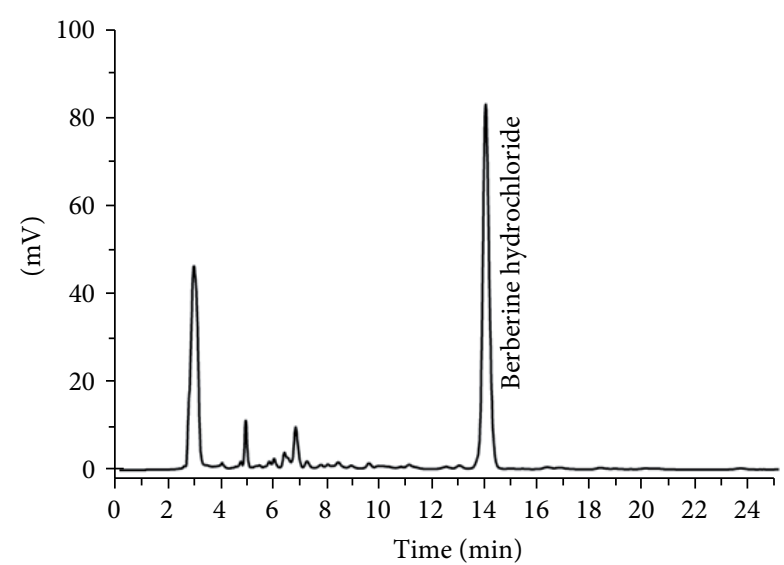

(b)

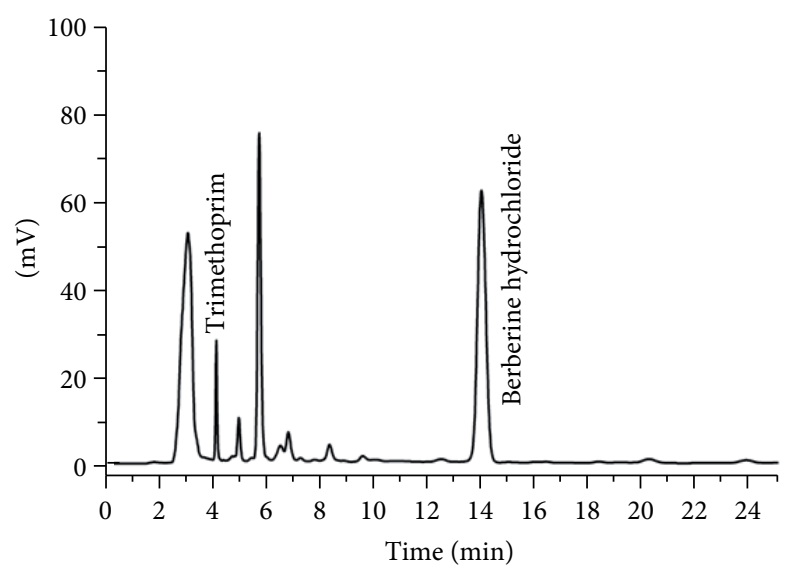

(c)

FIGURE 4: Typical HPLC chromatograms of oxidative degraded (a) trimethoprim, (b) berberine hydrochloride, and (c) combined capsule solutions.

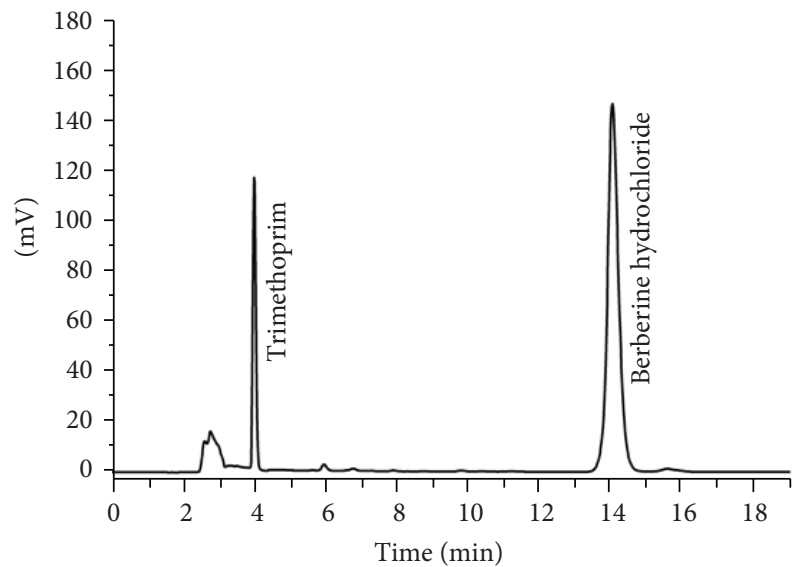

FIGURE 5: Typical HPLC chromatogram of combined capsule sample solution.

without interference from the excipients used to produce these commercially combined capsules.

\section{Conclusion}

In this study, a simple, sensitive, and specific stabilityindicating HPLC method has been developed and validated for simultaneous determination of BBR and TMP in pharmaceutical dosage form. This method was validated and found to be linear, accurate, precise, repeatable, specific, and selective for the detection and quantification of both drugs. Therefore, this method could be practically applied for routine quality control analysis of both compounds in bulk drugs and commercially combined capsule as well as applied to the analysis of samples obtained during stability study, contributing to improve the quality control and to assure the therapeutic efficacy of the TMP, BBR, and their combined preparation, thus facilitate the application of these drugs in clinical.

\section{Conflict of Interests}

The authors declared that they do not have a direct financial relation with the commercial identity mentioned in this paper that might lead to a conflict of interests for any of the authors. 


\section{Acknowledgment}

This research was financially supported by the Science and Technology Research Project from Education Department of Heilongjiang Province, China (Grant no. 12521629).

\section{References}

[1] W. Tan, Y. B. Li, M. W. Chen, and Y. T. Wang, "Berberine hydrochloride: anticancer activity and nanoparticula delivery system," International Journal of Nanomedicine, vol. 6, pp. 1773-1777, 2011.

[2] J. Y. Zhou and S. W. Zhou, "Berberine regulates peroxisome proliferator-activated receptors and positive transcription elongation factor b expression in diabetic adipocytes," European Journal of Pharmacology, vol. 649, no. 1-3, pp. 390-397, 2010.

[3] X. H. Liu, G. S. Li, H. Zhu et al., "Beneficial effect of berberine on hepatic insulin resistance in diabetic hamsters possibly involves in SREBPs, LXR $\alpha$ and PPAR $\alpha$ transcriptional programs," Endocrine Journal, vol. 57, no. 10, pp. 881-893, 2010.

[4] T. Singh, M. Vaid, N. Katiyar, S. Sharma, and S. K. Katiyar, "Berberine, an isoquinoline alkaloid, inhibits melanoma cancer cell migration by reducing the expressions of cyclooxygenase-2, prostaglandin E and prostaglandin E receptors," Carcinogenesis, vol. 32, no. 1, pp. 86-92, 2011.

[5] A. Burgeiro, C. Gajate, E. H. Dakir, J. A. Villa-Pulgarín, P. J. Oliveira, and F. Mollinedo, "Involvement of mitochondrial and B-RAF/ERK signaling pathways in berberine-induced apoptosis in human melanoma cells," Anti-Cancer Drugs, vol. 22, no. 6, pp. 507-518, 2011.

[6] S. M. Meeran, S. Katiyar, and S. K. Katiyar, "Berberineinduced apoptosis in human prostate cancer cells is initiated by reactive oxygen species generation," Toxicology and Applied Pharmacology, vol. 229, no. 1, pp. 33-43, 2008.

[7] M. A. James, H. Fu, Y. Liu, D. R. Chen, and M. You, "Dietary administration of berberine or Phellodendron amurense extract inhibits cell cycle progression and lung tumorigenesis," Molecular Carcinogenesis, vol. 50, no. 1, pp. 1-7, 2011.

[8] I. A. Lee, Y. J. Hyun, and D. H. Kim, "Berberine ameliorates TNBS-induced colitis by inhibiting lipid peroxidation, enterobacterial growth and NF- $\kappa$ B activation," European Journal of Pharmacology, vol. 648, no. 1-3, pp. 162-170, 2010.

[9] H. Y. Zhou and S. Mineshita, "The effect of berberine chloride on experimental colitis in rats in vivo and in vitro," Journal of Pharmacology and Experimental Therapeutics, vol. 294, no. 3, pp. 822-829, 2000.

[10] M. Wu, J. Wang, and L. T. Liu, "Advance of studies on antiatherosclerosis mechanism of berberine," Chinese Journal of Integrative Medicine, vol. 16, no. 2, pp. 188-192, 2010.

[11] B. H. Kim, M. Kim, C. H. Yin et al., "Inhibition of the signalling kinase JAK3 alleviates inflammation in monoarthritic rats," British Journal of Pharmacology, vol. 164, no. 1, pp. 106-118, 2011.

[12] C. L. Kuo, C. W. Chi, and T. Y. Liu, "The anti-inflammatory potential of berberine in vitro and in vivo," Cancer Letters, vol. 203, no. 2, pp. 127-137, 2004.

[13] G. Granero, C. Garnero, and M. Longhi, "Second derivative spectrophotometric determination of trimethoprime and sulfamethoxazole in the presence of hydroxypropyl- $\beta$ cyclodextrin (HP- $\beta$-CD)," Journal of Pharmaceutical and Biomedical Analysis, vol. 29, no. 1-2, pp. 51-59, 2002.
[14] S. R. Bushby and G. H. Hitchings, "Trimethoprim, a sulphonamide potentiator," British Journal of Pharmacology, vol. 33, no. 1, pp. 72-90, 1968.

[15] P. A. Masters, T. A. O’Bryan, J. Zurlo, D. Q. Miller, and N. Joshi, "Trimethoprim-sulfamethoxazole revisited," Archives of Internal Medicine, vol. 163, no. 4, pp. 402-410, 2003.

[16] B. Xu and L. M. Gao, "Determination of berberine hydrochloride and trimethoprim in capsulae berberine et trimethoprim by HPLC," Chinese Journal of Pharmaceutical Analysis, vol. 21, no. 1, pp. 21-23, 2001.

[17] Y. X. Chang, Y. Q. Qiu, L. M. Du, C. F. Li, and H. Wu, "Simultaneous determination of palmatine and berberine using cucurbit[7]uril as mobile phase additive by HPLC," Journal of Liquid Chromatography \& Related Technologies, vol. 34, no. 20, pp. 2629-2639, 2011.

[18] Z. G. Wang, Q. Du, X. Qiu et al., "Simultaneous determination of six herbal components in intestinal perfusate by highperformance liquid chromatography," Biomedical Chromatography, vol. 23, no. 8, pp. 798-803, 2009.

[19] J. B. Chen, H. M. Zhu, V. M. Chu et al., "Quality control of a herbal medicinal preparation using high-performance liquid chromatographic and capillary electrophoretic methods," Journal of Pharmaceutical and Biomedical Analysis, vol. 55, no. 1, pp. 206-210, 2011.

[20] W. Li, S. B. Yang, Z. F. Pi et al., "Separation and determination of alkaloids in rhizoma corydalis by capillary zone electrophoresis," Journal of Liquid Chromatography \& Related Technologies, vol. 34, no. 12, pp. 1050-1061, 2011.

[21] S. P. Liu, Z. Yang, Z. F. Liu, J. T. Liu, and Y. Shi, "Resonance Rayleigh scattering study on the interaction of gold nanoparticles with berberine hydrochloride and its analytical application," Analytica Chimica Acta, vol. 572, no. 2, pp. 283-289, 2006.

[22] N. Dong, L. N. Cheng, X. L. Wang, Q. Li, C. Y. Dai, and Z. Tao, "Significant fluorescence enhancement by supramolecular complex formation between berberine chloride and $\operatorname{cucurbit}(n=7)$ uril and its analytical application," Talanta, vol. 84, no. 3, pp. 684-689, 2011.

[23] F. Wang, Y. M. Gao, L. Gao, and T. L. Xing, "Study on the electrochemical behavior of the anticancer herbal drug berberine and its analytical application," Journal of the Chinese Chemical Society, vol. 58, no. 4, pp. 450-456, 2011.

[24] X. Q. Xu, Q. A. Lin, X. Y. He, F. F. Fu, and G. N. Chen, "Determination of protoberberine alkaloids in medicinal plants based on acidic potassium permanganate chemiluminescence system," Luminescence, vol. 25, no. 5, pp. 403-408, 2010.

[25] D. C. G. Bedor, T. M. Gonçalves, M. L. L. Ferreira et al., "Simultaneous determination of sulfamethoxazole and trimethoprim in biological fluids for high-throughput analysis: comparison of HPLC with ultraviolet and tandem mass spectrometric detection," Journal of Chromatography B, vol. 863, no. 1, pp. 46-54, 2008.

[26] E. P. Papapanagiotou, E. G. Iossifidou, I. E. Psomas, and G. Photis, "Simultaneous HPLC determination of sulfadiazine and trimethoprim in cultured gilthead sea bream (Sparus aurata, L.) tissues," Journal of Liquid Chromatography and Related Technologies, vol. 23, no. 18, pp. 2839-2849, 2000.

[27] R. Fernandez-Torres, M. O. Consentino, M. A. B. Lopez, and M. C. Mochon, "Simultaneous determination of 11 antibiotics and their main metabolites from four different groups by reversedphase high-performance liquid chromatography-diode arrayfluorescence (HPLC-DAD-FLD) in human urine samples," Talanta, vol. 81, no. 3, pp. 871-880, 2010. 
[28] A. Ghanem, M. Meshali, and A. Foda, "Simultaneous spectrophotometric determination of trimethoprim and sulphamethoxazole in pharmaceutical preparations," Journal of Pharmacy and Pharmacology, vol. 31, no. 2, pp. 122-123, 1979.

[29] D. Bonazzi, V. Andrisano, A. M. Di Pietra, and V. Cavrini, "Analysis of trimethoprim-sulfonamide drug combinations in dosage forms by UV spectroscopy and liquid chromatography (HPLC)," Farmaco, vol. 49, no. 6, pp. 381-386, 1994.

[30] F. E. B. Silva, M. F. Ferrão, G. Parisotto, E. I. Müller, and E. M. M. Flores, "Simultaneous determination of sulphamethoxazole and trimethoprim in powder mixtures by attenuated total reflection-Fourier transform infrared and multivariate calibration," Journal of Pharmaceutical and Biomedical Analysis, vol. 49, no. 3, pp. 800-805, 2009.

[31] International Conference on Harmonization (ICH), Technical Requirements for the Registration of Pharmaceutical for Human Use, Stability Testing of New Drugs Substance and Products Q1A(R2), Geneva, Switzerland, pp. 1-18, 2003.

[32] M. D. Diego, S. Mennickent, G. Godoy, and V. A. Miranda, "Validated stability-indicating LC method for simultaneous determination of enalapril and hydrochlorothiazide in pharmaceutical samples," Current Pharmaceutical Analysis, vol. 7, no. 4, pp. $248-252,2011$ 

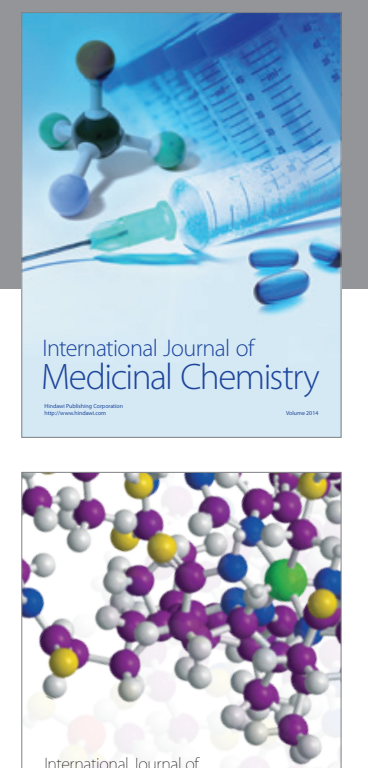

\section{Carbohydrate} Chemistry

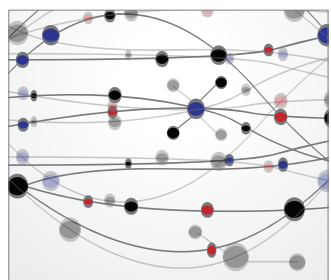

The Scientific World Journal
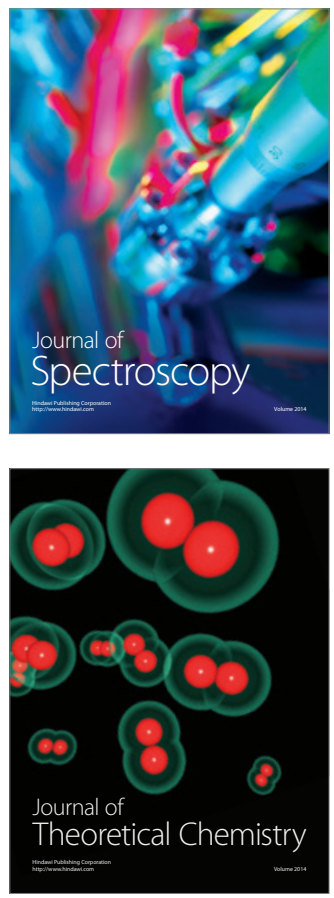
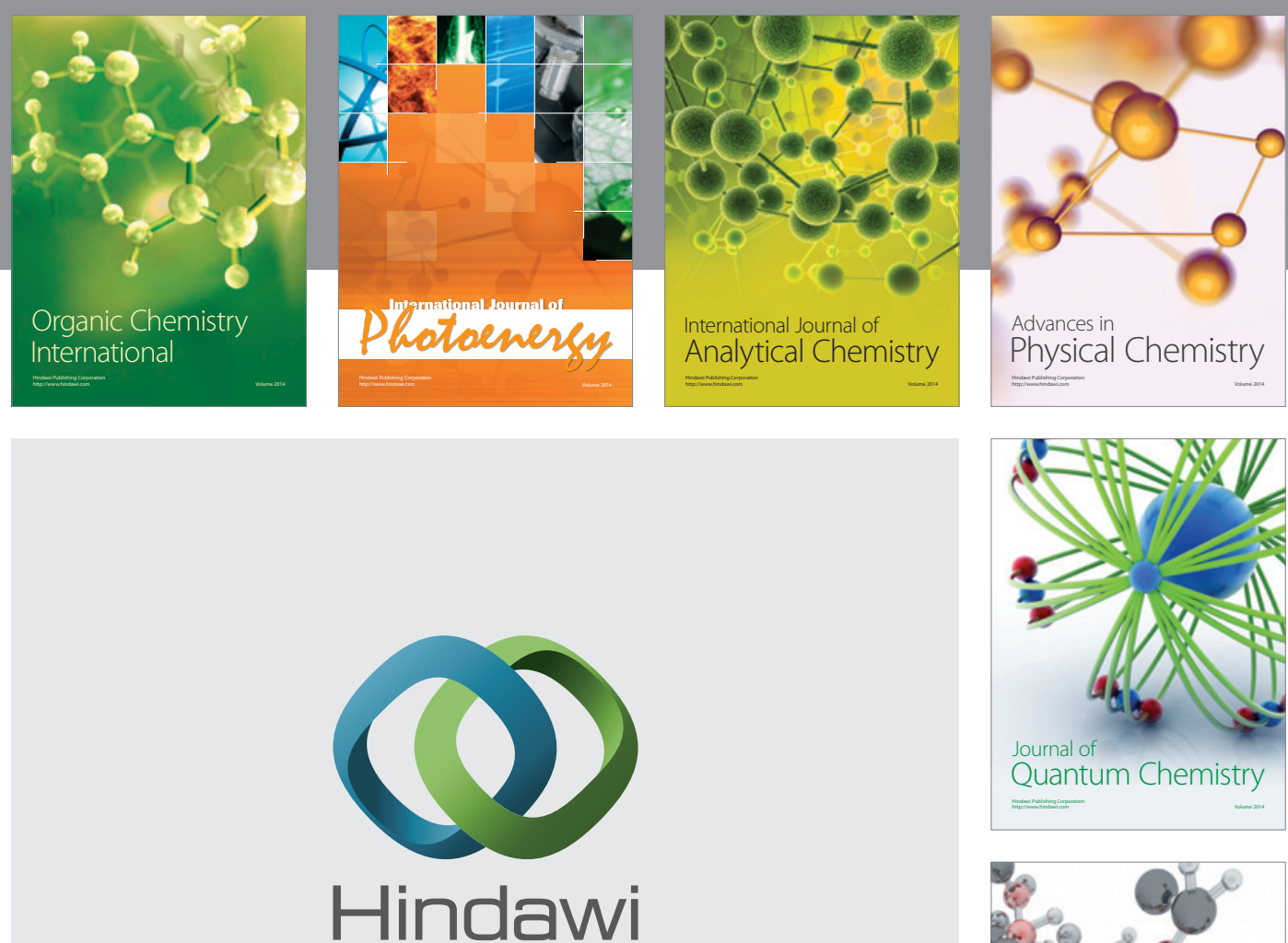

Submit your manuscripts at

http://www.hindawi.com

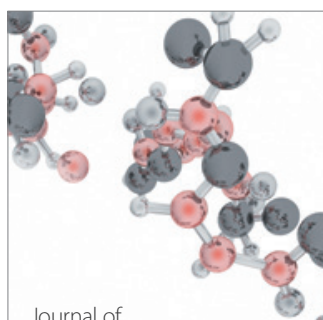

Analytical Methods

in Chemistry

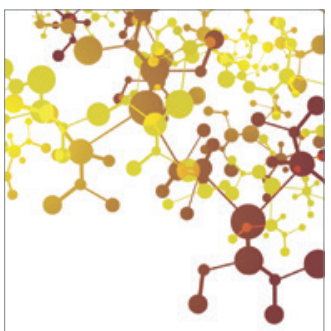

Journal of

Applied Chemistry

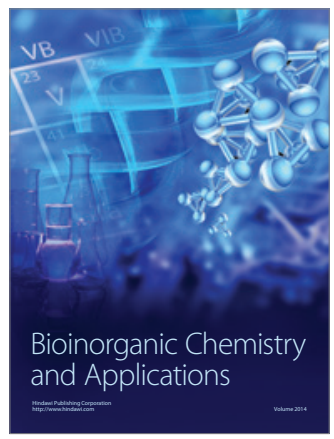

Inorganic Chemistry
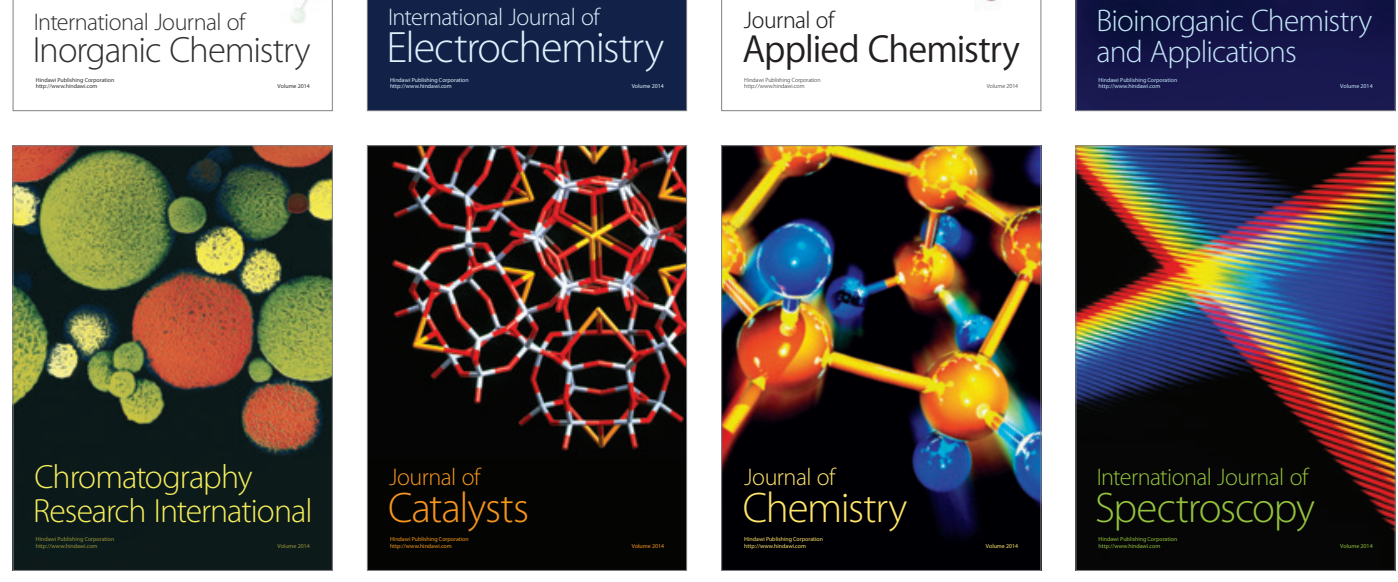